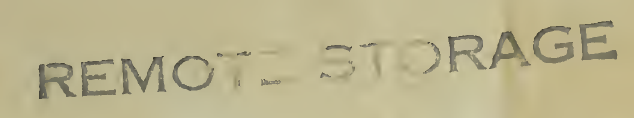

[Reprinted from Biological Buliterin, Vol. IX., No. 6, November, 1905.]

\title{
OBSERVATIONS ON THE PROGENY OF VIRGIN ANTS.
}

ADELE M. FIELDE.

The value of the experimental work here presented lies mainly in the complete protection of the virginity of the ant-mothers during their whole lifetime, or from their pupa-stage to the close of the experiments undertaken with them, and in the perfect safeguarding of their eggs from contact with spermatozoa outside the body of the ant.

At the present time, so far as is known to the writer, published observations on the offspring of worker ants may be placed in three categories. Those in the first category present a possibility that a queen's eggs were inadvertently included in the nest with the workers sequestered. When ants are transferred from a natural to an artificial nest, it often happens that eggs, unobserved at the time of sequestration, are discovered in the new nest within a few days thereafter. Ants are tenacious of their charges, and they sometimes conceal eggs or small larvæ in their mouths, or carry them adhering to their persons. In this way eggs may be unwittingly transferred to the new abode and may afterward be brought together in a pile or packet, the observer believing them to be the product of the worker-ants when they are really the issue of a queen in the old habitation. Unless the ants were singly and carefully examined and freed from adherent eggs, or unless a longer time than the twenty days ordinarily required for incubation has elapsed since the segregation of the workers, there is reason for suspecting that the eggs may have been deposited by other ants than the sequestered ones.

In a second category may be included all those cases in which larvæ were intentionally introduced among the segregated ants. Such larvæ may not have reached the pupa-stage sooner than the issue from eggs deposited in the new nest, and it is impossible to maintain that the older and the younger larvæ are always distinguishable. I have had, in my artificial nests, larvæ of Cremastogaster lineolata, scarcely larger than the eggs from 
which they emerged, remaining for many months without visible growth, and then developing simultaneously with the issue of eggs deposited a half year later. I am informed by Dr. J. H. McGregor that larvæ of Camponotus americamus have remained such during ten months in his artificial nests at Columbia University; and by Dr. I. A. Field that larvæ of Camponotus pennsylvanicus remained under his observation in apparent good health and without visible growth for nearly fifteen months. Admitting that certain eggs were deposited by workers, we still lack assurance that introduced larvæe were not mingled with their issue, and thus there is created a reasoneble doubt as to the origin of the callows appearing in the nest at a later date.

To a third category we may relegate the numerous accounts, including my own, concerning the offspring of workers that had previously lived with males, and aiso those accounts in which male ants were hatched and permitted to remain within the segregated group of workers. We know that ants sometimes mate within the nest, and we have the results of many dissections indicating the capacity of certain workers for impregnation. Miss Holliday ${ }^{1}$ found not only ovaries but a seminal receptacle in certain individuals representing three genera of ponerine, two genera of myrmicine, and one species of camponotine workers, none of whom was externally distinguishable from its fellows. We can no longer consider the workers of all species of ants as sterile females. In view of the evidence that among workers, showing no difference in external structure there have been found, in numerous species, many members with both ovaries and seminal receptacles; and of the testimony of competent witnesses that the male ants sometimes pursue the workers with an ardor equal to that shown in their pursuit of the queens, we must abandon the long cherished notion that eggs deposited by worker ants are always unimpregnated.

We do not know even that ant-eggs may not be fecundated outside the body of the female, and this possibility should not be ignored in cases where the egg-piles are traversed by mature males in pursuit of queens and workers.

1 “A Study of some Ergatogynic Ants," Margaret Holliday. Contribution from the Zoölogical Laboratory of the University of Texas, June, I902. 
The absence of indubitable proof that the unfecundated antegg produces either male or female ant impelled me to undertake the formation of ant-groups in which no member had ever lived with a male, and from whose abode males were excluded. In the summer of 1904 I sequestered pupæ, with two or three workers to take care of them, in artificial nests in which there were neither queens nor males, and as soon as these pupæ hatched I segregated the callows in new nests into which no egg, larva or pupa was ever introduced. My ant-groups were thus made up of workers indubitably virgin, and the eggs deposited in their nests were certainly unimpregnated.

\section{Group A. Camponotus pictus.}

Group A consisted of thirty workers, majors and minors, of Camponotus herculeanus pictus, hatched between July I I and $3 \mathrm{I}$, I 904, and kept in segregation from their hatching until October, 1905. Their first eggs, ten in number, were deposited between May I 4 and 18, I905, and these had increased to about fifty on June 4. The first larva appeared on June 6 , nineteen days after the first eggs were observed. On July 7 the larvæ had made notable progress in number and in size, the largest then being as long as an adult worker. The first cocoon was spun on July i6, and the first offspring of these segregated virgin workers appeared on August I4. Between August I4 and September 30 their cocoons gave forth thirty-two notably large and sturdy males. That no female might escape observation if hatched from these cocoons, the cocoons were transferred, soon after their formation, to an annex of the nest where only five workers were admitted. Cocoons and nurses were daily counted, and it is certain no queen nor worker ever hatched from these cocoons.

\section{Group B. Formica argentata.}

Group B consisted of about fifty Formica argentata workers, all hatched from sequestered cocoons during September, I904, and kept in segregation by me from the time of hatching until after the close of this series of observations. From eggs deposited on July 7, 1905, the first larva appeared on July 19. The first cocoon was spun on August 4, and the first ant hatched 
on August 3 I. Only five cocoons were formed in this nest, and each of these rendered a large, fine male.

\section{Dr. Field's Group C. Formica argentata.}

Dr. Irving A. Field, who simultaneously with myself, sequestered pupae from the same wild west that provided my B group, likewise segregated virgin workers, to the number of one hundred and twenty-five, all hatched between August 20 and September 23, I904. From eggs laid between June 6 and I 3 , 1905, the first larva appeared on June $2 \mathrm{I}$; the first cocoon on July 23; and the first callow on August 7. All the young produced in this group were males, of which fourteen had appeared before September 3, 1905 .

\section{Dr. Field's Group D. Formica pallide-fulva fuscata.}

This group, while failing to meet prescribed conditions in so far as the workers were not sequestered during the whole of their lives, is herein inserted because its history is clearly recorded. It consisted of many workers, secured by Dr. Field, at Middlesex Fells, Mass., on March I 5, I 904. The ants were frozen in a mass when taken from the ground, and every ant was so carefully examined before her insertion into the artificial nest that there is no probability that eggs were introduced into the segregated group of workers. This group remained under Dr. Field's observation at Harvard University. It was placed in a chamber having a temperature of from $75^{\circ}$ to $85^{\circ} \mathrm{F}$. or from $23^{\circ}$ to $30^{\circ}$ C. On March 20, five days after the sequestration, the first egg was laid ; on April 4, the first larva appeared ; and on April I 7 , the first cocoon was spun. Before June Io, forty-six males had appeared in this nest; and no other than male young had been produced.

\section{Group E. Cremastogaster lineolata.}

The progeny of a queen ant whose life-experiences have all been under observation, is believed to be here for the first time enumerated.

On August I 8, I903, a queen Cremastogaster lineolata hatched in a sequestered group of pupæ in one of my artificial nests ${ }^{1}$

${ }^{1}$ My ants were under my care at the Marine Biological Laboratory at Woods Holl, Mass., during the summers, and at my home in New York City during the remainder of the year. 
and was immediately removed to a small nest, where there were several newly hatched workers and males of Stenamma fulvum, this group being originally created for observation of the behavior of a queen having a family made up of ants of other species than her own. When the queen was but a few days old, I clipped off her wings to secure her greater safety from accident among the viscid food-stuffs in the nest. During the ensuing year, all the males died, and three more were hatched from eggs deposited by the Stenamma workers. I did not expect this queen to lay eggs, because I had previously kept unmated queens (of Stenamma fulvum) a whole year without their losing their wings or depositing an egg during that period. Dr. McGregor also kept winged queens (of Camponotus americanus) ten months without their losing their wings or depositing eggs.

On July 3 I, I 904, I removed all the Stenammas from this nest, cleaned it thoroughly, and gave to the queen forty newly hatched workers from her own colony, probably her own sisters. Three days later there were ten eggs in the nest, and on August 2 I there were more than three hundred. That these eggs had been laid by the queen was indicated by their size and by the immaturity of all the workers in the nest. The queen was eight millimeters in length, the workers only three to four millimeters. Moreover, I compared the eggs with those of an isolated queen, Cremastogastcr lineolata, and found them to match precisely.

Young larvæ were first observed among the eggs on August 28 ; the first pupa appeared on December 22, 1904, and two males hatched on January 10, 1905. These, when a day old, were transferred to Dr. W. M. Wheeler for expert examination concerning signs of hybridization, and were by him reported to be typical Cremastogaster lineolata males. Their successors in the nest were like them. No male was permitted to mature in the nest, all except the first two being removed before hatching. Before the end of September, 1905, sixty-three males had been produced in this nest, the offspring of this virgin queen. No young queen or worker had been seen, though the pupæ in this species are always naked, and the young had been carefully examined at least twice a week.

While this Cremostogaster lineolata virgin queen was producing 
male offspring only, a queen, Camponotus pennsylvanicus, living in a similar nest of mine, supplied with the same food, subject to the same daily temperature, and having about the same number of worker-servants, produced numerous offspring, exclusively female. The Camponotus queen had been captured when deälated, presumably after her mating. Although these queens were of different subfamilies among the ants, the similarity in all the conditions of their environment except the incident of mating, points to a probability that the sex of their respective progeny was determined thereby, unimpregnated eggs producing males, and impregnated eggs producing females.

It is an interesting fact that during the twenty-six months that this Camponotus pennsylvanicus queen remained under my observation no male appeared among the many tens of her offspring ; while eleven of her segregated daughters in the care of Dr. Field produced at least three male, and no female, offspring.

The observations here recorded establish the view that some virgin workers lay eggs, and that many ant-eggs that have had no contact with spermatozoa produce males. Not until female progeny shall have been observed to issue from eggs protected as were those of my Camponotus pictus should we consider the Dzierzon theory inapplicable to ants. No ant indisputably virgin, with her eggs perfectly safeguarded from spermatozoa, has yet presented evidence against the extension of this theory to the Formicidæ.

MARINe BIOlOGical Laboratory, WoOD's Holl, Mass., September I 905. 
Digitized by the Internet Archive in 2017 with funding from

University of Illinois Urbana-Champaign Alternates 
